\title{
Novel axial flux machines topology assessment and their feasible applications
}

\author{
Kalpana Anumala, Ramesh Babu Veligatla \\ Department of Electrical \& Electronics Engineering, VNR Vignana Jyothi Institute of Engineering and Technology, \\ Hyderabad, India
}

\begin{tabular}{ll} 
Article Info & ABSTRACT \\
\cline { 1 - 2 } Article history: & $\begin{array}{l}\text { The axial flux machines (AFMs) which got discovered long back in } 1821 \\
\text { were shelved out due to their manufacturing complexities. These machines } \\
\text { are now reconsidered as novel topologies as their topology is well suitable }\end{array}$ \\
Received Sep 17, 2021 & $\begin{array}{l}\text { for fulfilling the present day technical and societal needs. An attempt has } \\
\text { been made in this paper to assess the different structures of Axial Flux } \\
\text { Accepted Jan 24, } 2022\end{array}$ \\
$\begin{array}{l}\text { Machines and to identify the feasible applications. The advantages of AFMs } \\
\text { have been highlighted in wind energy conversion systems and electrical } \\
\text { Keywords: }\end{array}$ & $\begin{array}{l}\text { vehicle applications. An exhaustive comparison has been carried out in this } \\
\text { work between the conventional radial flux and axial flux machines through } \\
\text { their sizing equations. }\end{array}$ \\
Axial flux machine & Electric vehicles
\end{tabular}

Finite element analysis

Radial flux machine

Wind energy conversion

This is an open access article under the CC BY-SA license. systems

\section{Corresponding Author:}

Kalpana Anumala

Department of Electrical and Electronics Engineering, VNR Vignana Jyothi Institute of Engineering and

Technology

JNTU, Hyderabad-500090, India

Email: anumala.kalpana@gmail.com

\author{
NOMENCLATURE \\ RFM : Radial flux machine \\ AFIM : Axial flux induction machine \\ WECS : Wind energy conversion system \\ PMSM : Permanent magnet synchronous machine \\ AFPM : Axial flux permanent magnet motor \\ TRAFIM : Twin rotor axial flux induction motor \\ RFIG : Radial flux induction generator \\ TRAFIG : Twin rotor axial flux induction generator
}

\section{INTRODUCTION}

The recent technological advancements in manufacturing and the availability of the materials in new combinations motivated for the face lifting of the axial flux machines in constructional and operational aspects. These machines offer high efficiency, low rotor losses and fairly good power and torque densities [1]. Since 1980, the applicability of axial flux machines has been reported to low-speed, direct-drive electrical drive requirements. The axial flux machine (AFM) promises for the exploitation of the active materials to high percentages than a classical radial flux machine (RFM). The AFMs comparatively use less material than RFMs. The AFMs require 13 to 14 percent less winding material say, copper and 21.5 to 32.5 percent less core material, generally the iron producing the same power output as that by AFMs and thus 
offer favorable power densities [2]-[4]. The topological differences between an AFM and a RFM are highlighted in the following Figure1.

Figure 1 (a) shows the radial flux machine in which flux direction is radial to the shaft axis and Figure 1 (b) shows axial flux machine wherein flux direction is axial to the shaft axis. In the axial flux machine, the active part to develop the voltage and electromagnetic torque is the radial length of the coil from stator inner radius to its outer radius. The active part of the machine is always in the radial direction and it increases with the number of poles and the axial flux machine is best suitable for low-speed applications since it has flexibility of having higher pole number [5]. The axial flux machines were reported to have reasonably high efficiency with reduced rotor losses and also have fairly good torque and power values [6].

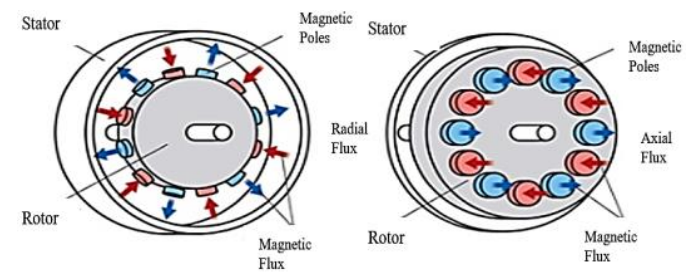

(a)

(b)

Figure 1. Differences between (a) radial flux machine and (b) axial flux machine

Since, the conductors are radially placed with machine axis; the axial lengths of these machines are short. This is especially a vital advantage when these AFMs are preferred for electric vehicle (EV) and wind energy conversion system (WECS) applications. Further, this particular machine configuration is proved as the most suited structure for low-speed high-torque industrial applications [7]-[9]. The axial flux machine was the first electric machine invented by faraday in 1821 [10]. But soon these machines got shelved out due to the drawbacks like one side magnetic pull which affects the bearings and manufacturing complexities. It required sophisticated manufacturing systems which has been added for its cost and made it expensive. The radial flux machines (RFMs) have taken over the edge in this regard and captured the market. But the present day societal and technological needs forced the researcher to rethink on the manufacturing of AFMs by advanced techniques and to make use these machines.

The axial flux machines (AFMs) differ from radial flux machines only in construction but principle of working is same [11]. In conventional RFMs, the conductors are placed in parallel to the shaft axis. The magnetic flux direction in the air-gap is radial between stator and rotor. But, in AFMs, the conducted are arranged in radial direction to shaft axis and the flux in air gap is axial to shaft axis. Hence, these machines are known as AFMs. These aspects are well illustrated in the Figure1. The stators of AFMs are of ring structure and its rotor is disc shaped. This disc shape of the rotor yields for low rotor inertia, high acceleration and makes the motor to come to the rest rapidly which is apt for robotic applications. Further, the air gap of AFM is planar and adjustable. The main dimensions that are considered in the design of axial and radial flux machines are highlighted in the Figure 2.

It is convenient to use the radial flux (RF) machines in Figure 2 (a) when the $\lambda \mathrm{R}$ value of the motors is greater than 1 being $\lambda \mathrm{R}$ is the ratio of motor overall axial length to the motor external diameter $(\lambda \mathrm{R}=\mathrm{Lt} /$ D0). The AF machines as shown in Figure 2 (b) are attractive for flat geometries $(\lambda \mathrm{A}=\mathrm{Le} / \mathrm{Dt}<0.3)$ with high pole numbers. Apart from the one side magnetic pull and complex manufacturing techniques, the other reasons for AFMs to not gain much popularity during initial stage are huge one side thrust or axial magnetic pull-on bearings, increased production cost, assembling complications and keeping air-gap uniform and stable. The contact surface between rotor and shaft does not increase in the same proportion of power output.

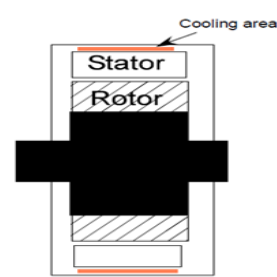

(a)

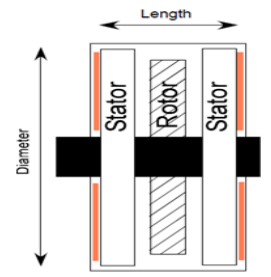

(b)

Figure 2. Dimensions of (a) radial flux and (b) axial flux machines 


\section{AXIAL FLUX MACHINES-TYPES}

The brief categorization of axial flux machines is:

- Permanent magnet synchronous machines

- Asynchronous or induction machines

- Interior permanent magnet synchronous machines

Depending upon the direction of flux, winding arrangement and magnet configurations, the AFMs are classified.

\subsection{Permanent magnet synchronous AFMs}

The topological differences between a single and multiple air-gaps permanent-magnet synchronous machine (PMSM) machines are highlighted in Figure 3. The internal stator and external rotor (ISER) and external stator and internal rotor (ESIR) structures are the two distinct types of multiple air gap axial flux machines. In single airgap machines have single stator and single rotor which is shown in Figure 3 (a). These ISER type machines have got ' $\mathrm{N}$ ' number of stators and ' $(\mathrm{N}+1)$ ' number of rotors. In this pattern, the stator is sandwiched between two rotors and this arrangement makes the end winding connection shorter as shown in Figure 3 (b). Hence, the efficiency gets improved. On the other hand, the ESIR types have (N+1) stators and $\mathrm{N}$ rotors. Also, rotor is located between two stators. Also because of large end winding on stator the efficiency of machine is very less as compared with the ISER type.
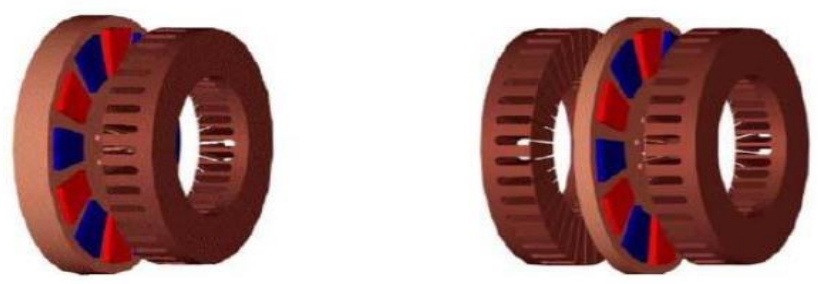

Figure 3. Single air-gap and multi air-gap AFM

By the way the flux directed in the stator, the possible topologies of ISER are N-N (north-north) type and NS (north-south) type and these clearly represented in Figure4. The stator core in NN type machine must be very broad to promote the return flux path. The flux direction in the air-gap is axial and in stator core it is axial and radial. The stator of the NS type ISER has lap winding and this lap winding leads to have more copper as shown in Figure 4. The flux is axially directed in both stator core and air gap in NS type ISER. It requires less stator core due to large end winding. Also, the ISER type machines are further categorized intoslotted and non-slotted types. The NN type topology exists in non-slotted type axial machine where as both NN and NS types available in slotted type AFMs.

From aforementioned classification various types of PMSM and Induction machines are extracted. The PMSM are again divided into two types,

- Surface mounted permanent magnet (SMPM)

- Interior permanent magnet PMSM.

The SMPM are two types-slotted or non-slotted. These machines are used with high energy magnets. The flux direction is from south to north as shown in Figure 5.

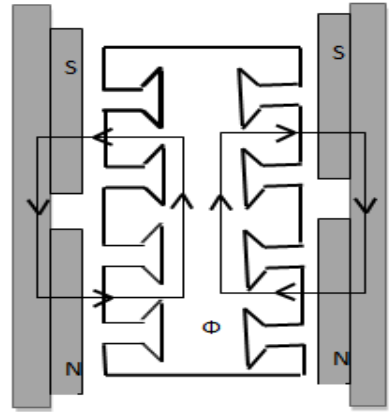

Figure 4. TORUS NN-type SMPM machine

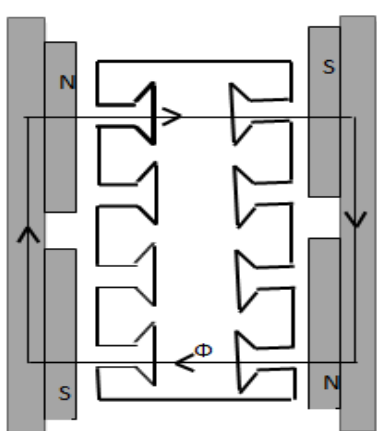

Figure 5. TORUS NN-type SMPM machine 
To overcome the limitations of permanent magnet machines and to prevent the demagnetizing armature currents, a new axial flux SMPM machine has been recommended [12]. The field winding is arranged between the two stator cores and permanent magnets and iron pieces are accommodated on rotor. The air-gap flux can be regulated by varying the current passing through the field winding. This topology is called field controlled PM machine topology and the concept is illustrated in Figure 6. The Figure6 shows field controlled SMPM machine with single stator and dual rotor axial flux induction motor (AFIM).

The wind turbine generators are classified as (i) geared drive wind turbine and (ii) direct drive wind turbine [13]. The traditional radial flux machines have the drawbacks of high inertia, low torque to volume ratio, long axial length; the axial-flux permanent-magnet (AFPM) machines are preferred for direct drive wind turbines. The slots less type AFPM machines are drawing attention in the direct coupling wheel type motors in electric or hybrid cars with power electronic interface avoiding the engine and mechanical transmission.

\subsection{Induction or asynchronous AFMs}

Generally, the axial flux induction machines are of either single air gap type or dual air-gap type. These machines are of slotted type which carries three phase winding. In dual rotor and single stator type machines, the two independent rotors drive at two different loads which give two different speeds. The possible topologies in AFIM are slotted NN and slotted NS type as depicted in Figure 7. The core of an AFIM can be of solid type or laminated type. It is usually built with strip wound circular core and its slots are radially punched. Rotor is manufactured using laminated steel or solid steel. These are laminated to reduce the eddy currents in the core. For high speed applications the solid rotor is selected since the laminated steel has weak mechanical property [14]-[17].

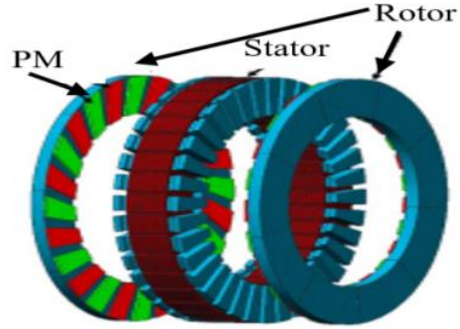

Figure 6. Field controlled SMPM AFIM

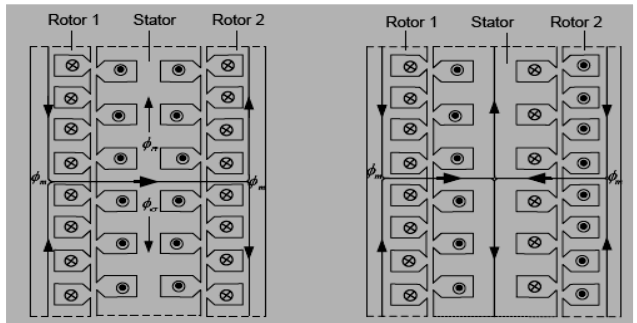

Figure 7. Slotted NS and NN-type AFIM

In many industrial applications, the gear boxes are used to get the required rotational speed for the machine. By replacing gear box with electric motor reduces the maintenance cost and also reduces the space which improves the reliability and performance of the machine. This can be obtained by using axial flux induction machine. The twin rotor axial flux induction motors with two independent shafts with single converter is employed by replacing engine and the mechanical differential in traditional in-wheel motors with two independent power electronic converters in electric vehicles.

Generally, for low power domestic applications, single phase axial flux induction motors are adapted. The low power domestic applications are like fans, pumps and food processors, since in these machines the rotor is integrated with the rotating mechanical load. The AFIM are appropriate choice for high speed and servo applications since these machines are designed to have smaller or larger inertia [18], [19]. Due to excellent mechanical and dynamical performance and light constructional properties of AFIM makes the axial flux induction possible. Nowadays the axial flux induction motors are increasingly used with variable speed drives of very power ratings. Also, solid rotor axial flux induction machine is more suitable option to integrate with a diesel engine turbo charger with a speed of $130 \mathrm{Krpm}$.

\section{COMPARISON BETWEEN AFM AND RFM}

The comparison between RFM and AFM are performed using the "sizing equations". These equations represent the output power $P_{R}$ as a function of the overall volume of the machine. The sizing equations for conventional radial and axial flux machines have been presented in this paper.

For Permanent magnet axial flux machines:

The permanent magnet AFMs and RFMs sizing equations are shown below: For radial flux machines, 


$$
\mathrm{P}_{\mathrm{R}}=\frac{1}{1+\mathrm{K}_{\emptyset}} \frac{\mathrm{m}}{\mathrm{m} 1} \frac{\Pi}{2} \mathrm{~K}_{\mathrm{e}} \mathrm{K}_{\mathrm{i}} \mathrm{K}_{\mathrm{p}} \eta \mathrm{B}_{\mathrm{g}} \mathrm{A} \frac{\mathrm{f}}{\mathrm{p}} \lambda_{\mathrm{o}}^{2} \mathrm{D}_{\mathrm{o}}^{2} \mathrm{~L}_{\mathrm{e}}
$$

where, aspect ratio for radial flux machine is $\mathrm{k}_{\mathrm{l}}=\frac{\mathrm{L}_{\mathrm{e}}}{\mathrm{D}_{\mathrm{g}}}$, For axial flux machines,

$$
\mathrm{P}_{\mathrm{R}}=\frac{1}{1+\mathrm{K}_{\emptyset}} \frac{\mathrm{m}}{\mathrm{m} 1} \frac{\Pi}{2} \mathrm{~K}_{\mathrm{e}} \mathrm{K}_{\mathrm{i}} \mathrm{K}_{\mathrm{p}} \eta \mathrm{B}_{\mathrm{g}} \mathrm{A} \frac{\mathrm{f}}{\mathrm{p}}\left(1-\lambda^{2}\right) \frac{1+\lambda}{2} \mathrm{D}_{\mathrm{o}}^{3}
$$

the machine power density equation for total volume is given by (for radial flux machines),

$$
P_{d e n}=\frac{P_{R}}{\frac{\pi}{4} d_{t}^{2} L_{t}}
$$

here, the total length of the machine=Lt in the axial direction. For axial flux machines,

$$
P_{\text {den }}=\frac{P_{R}}{\frac{\pi}{4} d_{t}^{2} L_{e}}
$$

where, $\mathrm{Dt}=$ The total outer diameter of the machine.

The stack outer diameter and protrusion includes total outer diameter from the iron stack in radial direction. To identify the maximum power density of AF machines, the Permanent magnet axial flux machine with single stator and twin rotor configuration has been examined. In this diameter ratio $(\lambda)$ plays an important role. The nominal power and rotational speed of the machine is $12 \mathrm{KW}$ and $700 \mathrm{rpm}$ with number poles $\mathrm{N}=8$. The power density and axial lengh are inversely proportional which is shown in Figure 8 . The Figure 9 shows the power density variation with diameter ratio $\lambda$ at constant flux density in air gap $(0.8 \mathrm{~T})$.

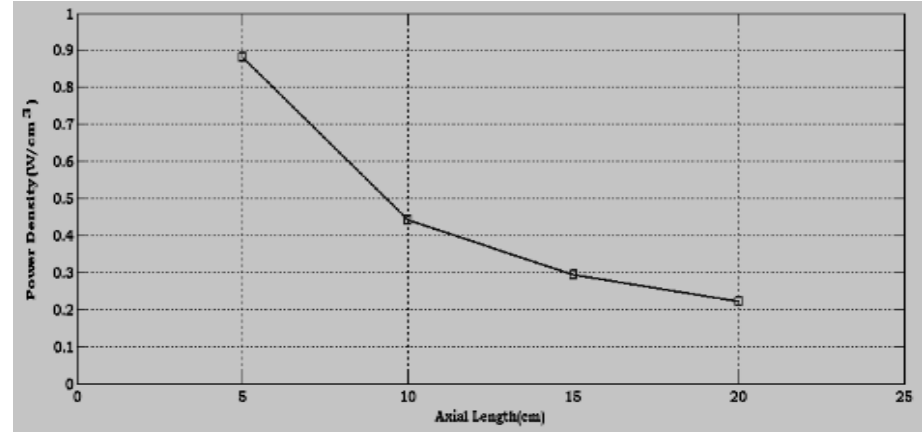

Figure 8. Power density Vs axial length

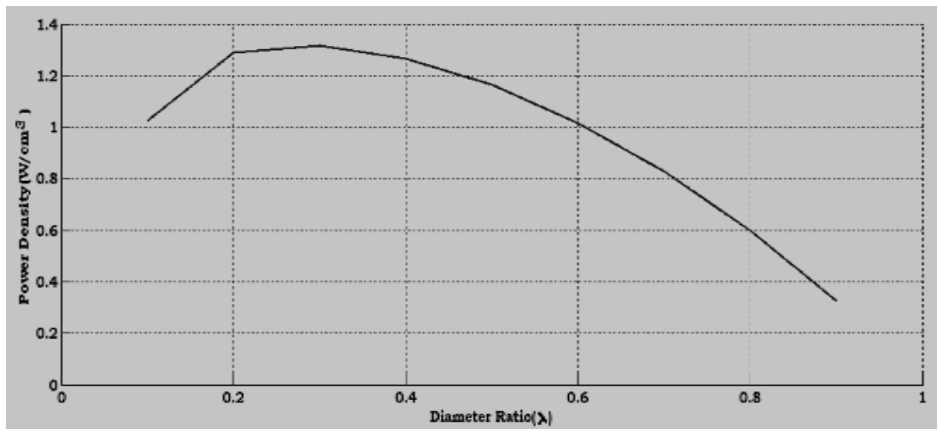

Figure 9. Power density Vs diameter ratio $(\lambda)$

To improve the performance of the AF machines, the diameter ratio must be chosen carefully. By considering the axial length and protrusion of end winding from the iron stack in radial direction, the value of $\lambda$ is 0.3 and corresponding flux density in air-gap and maximum power density are $1.315 \mathrm{w} / \mathrm{cm}^{3} \& 0.8 \mathrm{~T}$. [20]. For axial flux induction machines:

The sizing equations for Single air gap axial flux induction machines: 


$$
P_{R(I M)}=\frac{\sqrt{2 \pi^{2}}}{16\left(1+K_{\varphi}\right)} K_{w} B_{g} A \frac{f}{p}\left(D_{O}+D_{i}\right)^{2}\left(D_{O}-D_{i}\right) \eta \cos \emptyset_{r}
$$

The sizing equations for dual air gap axial flux induction machines:

$$
\begin{aligned}
& P_{R(I M)}=\frac{\sqrt{2 \pi^{2}}}{8\left(1+K_{\varphi}\right)} K_{w} B_{g} A \frac{f}{p}\left(D_{O}+D_{i}\right)^{2}\left(D_{O}-D_{i}\right) \eta \cos \emptyset_{r} P_{R(I M)} \\
& =\frac{\sqrt{2 \pi^{2}}}{8\left(1+K_{\varphi}\right)} K_{W} K_{L} B_{g} A \frac{f}{p}\left(D_{O}+D_{i}\right)^{2}\left(D_{O}-D_{i}\right) L_{e} \eta \cos \emptyset_{r}
\end{aligned}
$$

(In terms of $\mathrm{L}_{\mathrm{e}}$ )

\section{APPLICATIONS OFAXIAL FLUX MACHINES}

The axial flux machines have been used in many automotive applications such as electric vehicles and renewable energy conversion systems. They have specific advantages for integration into hybrid power trains where available length is limited due to their disk-like design.

\subsection{Wind energy conversion systems (WECS)}

The conventional WECS, the induction generators are coupled with multi-stage gear box which causes for mechanical transmission losses. This lets the system efficiency to fall. The multi stage transmission systems (gear-box) have always significant losses and the typical range of these losses have been reported between approximately $5-10 \%$. To minimize these losses and also to limit the number of stages to single, the axial flux induction generators have been introduced in place of conventional induction generators or double-fed induction generators (DFIGs). The more number of poles can be accommodated in its stator since axial flux machines are designed to have smaller axial length and larger in diameter. So, the rotor can operate at lower synchronous speeds. Therefore these machines are best suited for wind energy conversion systems.

Inwind turbine, the output power is proportional to square of the blade length. The increase in power output in WECS requires the considerable increase of the blade length. This causes for increase in the cost of the foundation and towers. To enhance or to increase the power output in WECS, the TRAFIM is best suitable induction machine. The reactive power compensation is very essential in induction generators since these machines are associated with large amount of reactive power. To compensate this reactive power flow in conventional WECS, a thyristor switched capacitor (TSC)-thyristor controlled reactor (TCR) is used in proposed system. The Figure10 shows the implementation of TRAFIM in wind energy conversion system. In the proposed system, to compensate the reactive power, TSC-TCR type SVC is employed. The output powers of conventional RFIG and TRAFIG are compared and simulation results are presented in Figure 11.

In TRAFIM, the output power is enhanced two times as that produced using a conventional radial flux induction generator. The Figure 11 shows variation of output power with speed for single airgap and twin rotor AFIG. The Figure 12 depicts the compensation of power factor with and without TSC-TCR [21], [22]. Figure 13 shows variation of reactive power w.r.t power factor with and without SVC w.r.t speed with TSC-TCR.

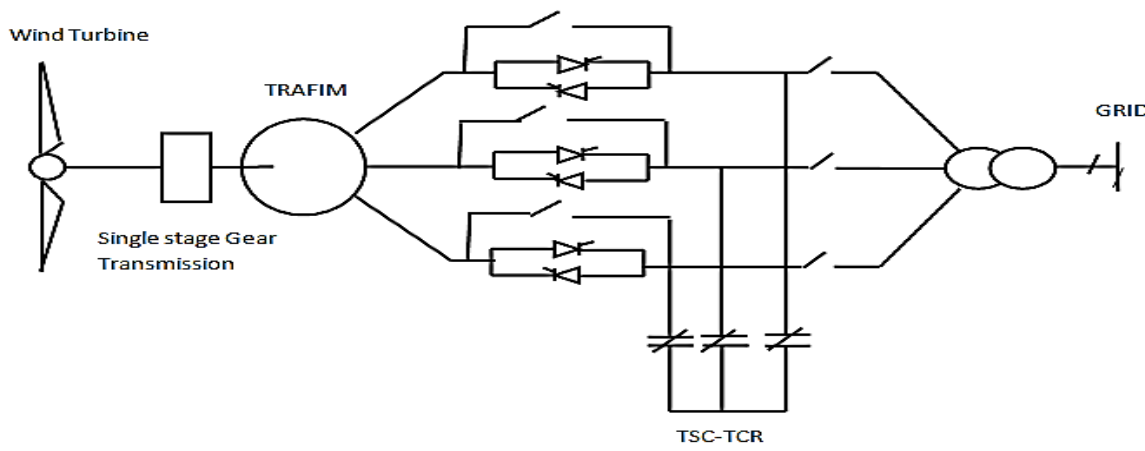

Figure 10. Implementation of twin rotor AFIG in WECS 


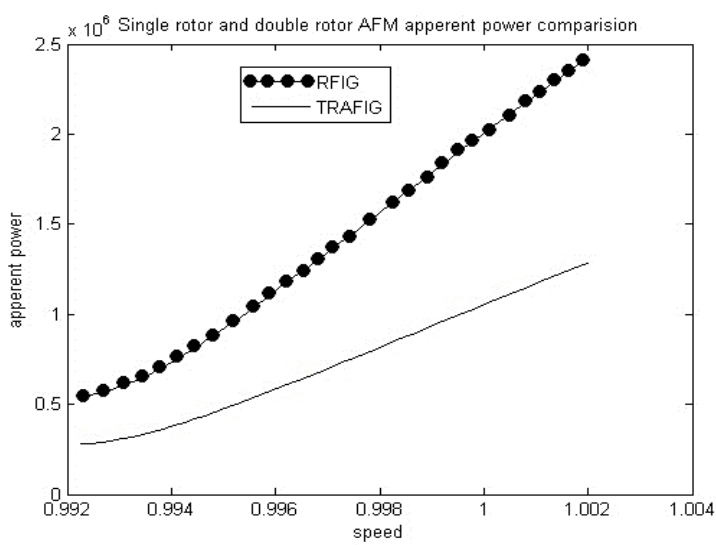

Figure 11. Output power of single air gap and TRAFIG

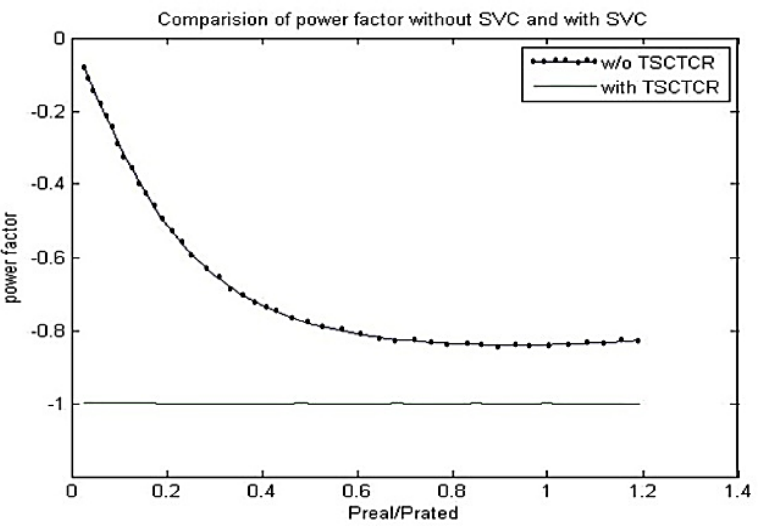

Figure12. Power factor with and without TSC-TCR

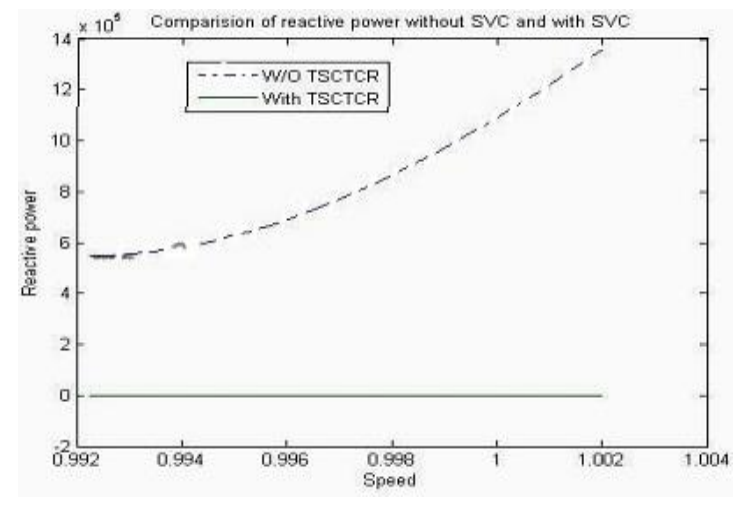

Figure 13. Reactive power of TRAFIG with and without SVC

\subsection{Electric vehicle applications}

The conventional IC engine vehicle causes environmental damage and in-efficient utilization of energy. These conventional vehicles involves bulky and heavy mechanical differential which causes mechanical losses and ultimately the system efficiency may decrease [23], [24]. The electrical vehicles gives appropriate solution to these forementioned drawbacks and also the efficiency of the system increases. In electric vehicle, the TRAFIM is used as a propulsion motor. The axial flux permanent magnet machine provides high torque densities with high energy magnets and large air-gap. This novel TRAFIM performs both the functions of engine and the differential in single drive unlike the functions of conventional IC engine vehicles. The Figure14 shows twin rotor axial flux induction motor with two different shafts driving two independent rotors. The rotor 1 rotates with speed N1 rpm and rotor 2 rotates with speed N2 rpm [25].

The following Figures 15 and 16 depicts the instantaneous values of torques and speeds exerted by the two rotors during a curvature motion of the vehicle. Figure 15 shows variation of rotor instantaneous speed with time in synchronously rotating reference frame and Figure16 shows variation of rotor instantaneous torque with respect to time in synchronously rotating reference frame.

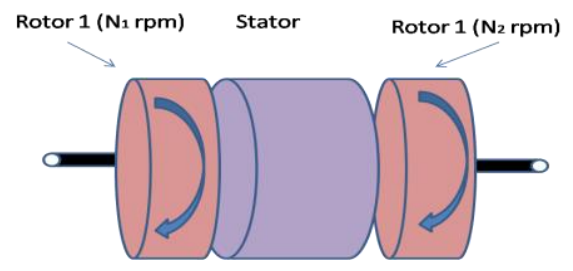

Figure 14. TRAFIM with two-independent rotors 


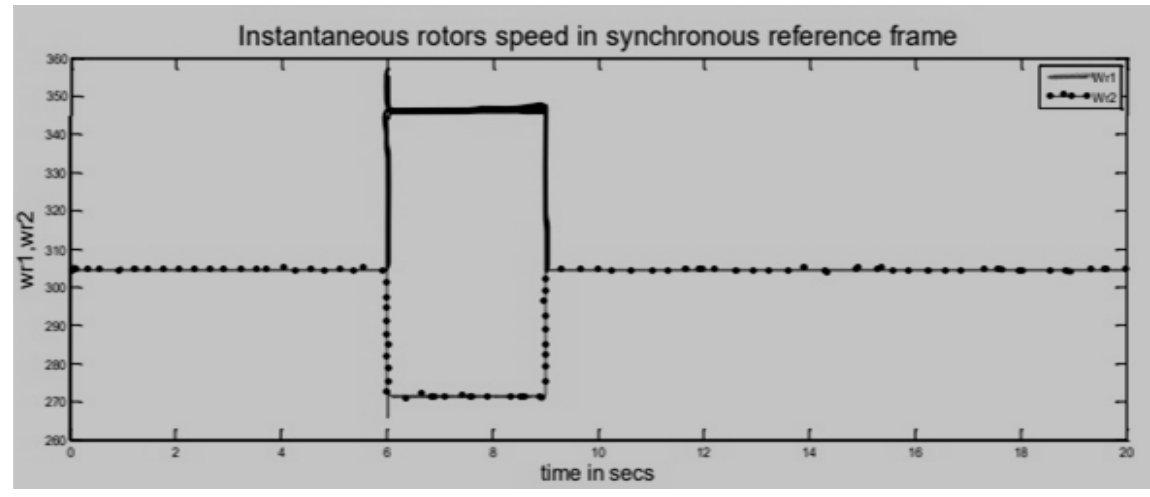

Figure 15. Rotor instantaneous speed

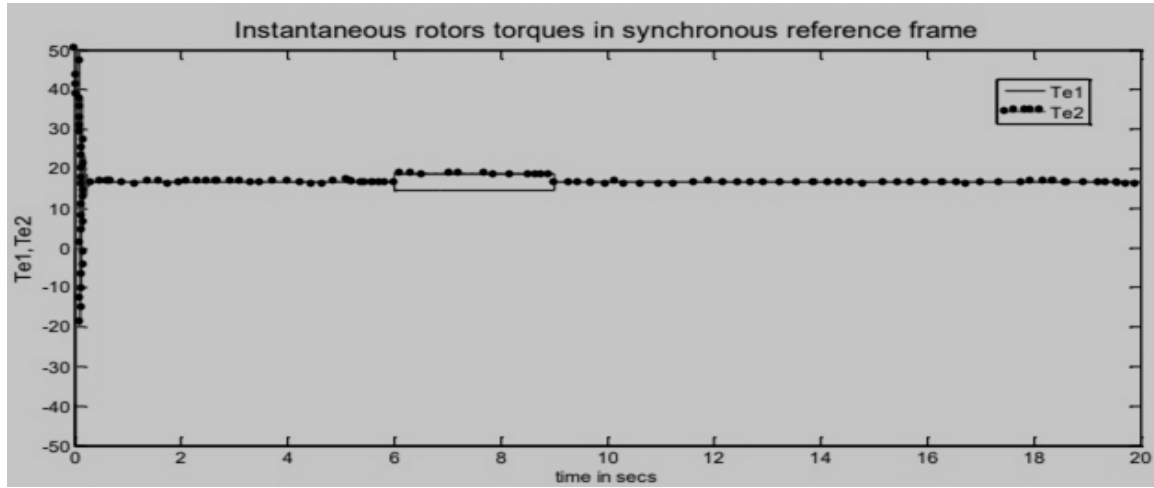

Figure 16. Rotor instantaneous torque in synchronously rotating reference frame

\section{CONCLUSIONS}

An exhaustive literature survey has been conducted on axial flux machines and presented in this paper in a lucid way. For low speed and high torque applications, the AFM is the optimal option. The various AFM topologies were discussed. The general-purpose sizing algorithms are based on a comparison between traditional radial and axial flux machines. The feasible applications of AFMs have discussed especially in wind energy conversion systems and electric vehicle mobility fields with the support of simulation results.

\section{REFERENCES}

[1] S. Huang, J. Luo, F. Leonardi, and T. A. Lipo, "A comparison of power density for axial flux machines based on general purpose sizing equations," IEEE Transactions on Energy Conversion, vol. 14, no. 2, pp. 185-192, 1999, doi: 10.1109/60.766982.

[2] P.D. Evans, and J.E. Eastham, "Disk-geometry homopolar synchronous machines,"IEEE Proceedings, vol. 127, no. 5, pp. 299307, 1980, doi: 10.1049/ip-b.1980.0039.

[3] M. Valtonen, A. Parviainen, and J. Pyrhonen, "Influence of the air-gap length to the performance of an axial-flux induction motor," 18th International Conference on Electrical Machines, 2008, pp. 1-5, doi: 10.1109/ICELMACH.2008.4800002.

[4] M. Valtonen, "Performance Characteristics of an Axial-FluxSolid-Rotor-Core Induction Motor," Phd Thesis, LappeenrantaUniversity of Technology, Lappeenranta, Finland, 2007.

[5] F. Caricchi, F. Crescimbini, and E. Santini, "Axial-Flux ElectromagneticDifferential Induction Motor," Electrical Machines and Drives, IEEE Conference Publication, no. 412, pp. 1-5, 1995.

[6] V. B. Honsinger, "Sizing Equations for Electrical Machinery," IEEE Transactions on Energy Conversion, vol. EC-2, no. 1, pp. 116-121, 1987, doi: 10.1109/TEC.1987.4765812.

[7] M. Valtonen, A. Parviainen, and J. Pyrhonen, "The Effects of the Number of Rotor Slots on the Performance Characteristics of Axial-Flux Aluminium-Cage Solid-Rotor Core Induction Motor," IEEE International Electric Machines \& Drives Conference, 2007, pp. 668-672, doi: 10.1109/IEMDC.2007.382747.

[8] W. S. Leung and C. C. Chan, "Axial-Field Electrical Machines - Design and Applications," IEEE Transactions on Energy Conversion, vol. EC-2, no. 2, pp. 294-300, June 1987, doi: 10.1109/TEC.1987.4765844.

[9] M. Valtonen, A. Parviainen, and J. Pyrhonen, "Influence of the air-gap length to the performance of an axial-flux induction motor," 18th International Conference on Electrical Machines, 2008, pp. 1-5, doi: 10.1109/ICELMACH.2008.4800002.

[10] M. S. M. Valtonen, D. S. A. Parviainen, and J. Pyrhonen, "Electromagnetic field analysis of 3D structure of axial-flux solid-rotor induction motor," International Symposium on Power Electronics, Electrical Drives, Automation and Motion, 2006, pp. 174-178, doi: 10.1109/SPEEDAM.2006.1649766. 
[11] A. Cavagnino, M. Lazzari, F. Profumo, and A. Tenconi, "A comparison between the axial flux and the radial flux structures for PM synchronous motors," IEEE Transactions on Industry Applications, vol. 38, no. 6, pp. 1517-1524, 2002, doi: 10.1109/TIA.2002.805572.

[12] M. Aydin, Surong Huang, and T. A. Lipo, "A new axial flux surface mounted permanent magnet machine capable of field control," Conference Record of the 2002 IEEE Industry Applications Conference 37th IAS Annual Meeting (Cat. No.02CH37344), 2002, vol. 2, pp. 1250-1257, doi: 10.1109/IAS.2002.1042719.

[13] H. Polinder, "Overview of and trends in wind turbine generator systems," IEEE Power and Energy Society General Meeting, 2011, pp. 1-8, doi: 10.1109/PES.2011.6039342.

[14] W. M. Arshad, T. Backstrom and C. Sadarangani, "Analytical design and analysis procedure for a transverse flux machine," IEMDC 2001. IEEE International Electric Machines and Drives Conference (Cat. No.01EX485), 2001, pp. 115-121, doi: 10.1109/IEMDC.2001.939284.

[15] G. B. Kilman, "Induction Disk Motor with Metal TapeComponents,"TORUS Concept Machines: Pre-Prototyping Design Assessment for Two Major TopologiesIEEE, US Patent no. 4363988, 1982.

[16] M. R. Dubois, H. Polinder, and J. A. Ferreira, "Comparison between Axial and Radial-Flux Permanent Magnet Generators for Direct-Drive Wind Turbines," Proc.European Wind Energy Conference and Exhibition, Copenhagen, 2001, pp.1112-1115.

[17] H. A. Hoseynabadi, P. J. Tavner, and H. Oraee, "Reliability comparison of direct-drive and geared drive wind turbine concepts," Wind Energy, vol, 13, pp. 62-73, 2009, doi: 10.1002/we.357.

[18] W. S. Leung and C. C. Chan, "Axial-Field Electrical Machines-Design and Applications," IEEE Transactions on Energy Conversion, vol. EC-2, no. 2, pp. 294-300, 1987, doi: 10.1109/TEC.1987.4765844.

[19] M. S. M. Valtonen, D. S. A. Parviainen, and J. Pyrhonen, "Electromagnetic field analysis of 3D structure of axial-flux solid-rotor induction motor," International Symposium on Power Electronics, Electrical Drives, Automation and MotionSPEEDAM, 2006, pp. 174-178, doi: 10.1109/SPEEDAM.2006.1649766.

[20] V R. Babu, G.S.Raju, and M.R. Chowdhary, "Tracing of maximum power density point for Axial Flux TORUS type machines using General Purpose Sizing equations," Proceedings of Seventeenth National Power System Conference (NPSC-2012)Power and Component stream held at Indian Institute of Technology (IIT-BHU), December 2012.

[21] V. R. Babu and M.P.Soni, "A Novel method of using Twin Rotor Axial Flux Induction Machine for Wind Energy Conversion System and the Reactive Power Compensation by TSC-TCR," International Journal of Emerging Technology and Advanced Engineering (IJETAE), vol. 2, no. 8, pp. 399-407, 2012

[22] V. R. Babu, P.Neelima and C. Manjeera, "Modelling of Axial Flux Induction Machine and its Application as Differential in Electric Vehicles," International Journal of Innovative Research in Advanced Engineering, vol. 1, no. 12, pp. 1-10, 2017, doi:10.17148/IJIREEICE.2017.5520.

[23] H. A. Toliyat, T. A. Lipo and J. C. White, "Analysis of a concentrated winding induction machine for adjustable speed drive applications. I. Motor analysis," IEEE Transactions on Energy Conversion, vol. 6, no. 4, pp. 679-683, 1991, doi: $10.1109 / 60.103641$

[24] Q. Hecker, J. Igelspacher, and H. Herzog, "Parameter identification of an axial-flux induction machine by winding functions," The XIX International Conference on Electrical Machines - ICEM, 2010, pp. 1-6, doi: 10.1109/ICELMACH.2010.5608058.

[25] M. R. Dubois, "Review of electromechanical conversion inwindturbines," Direct Drive Wind Turbine, pp. 1-93, 2000, doi: 10.13140/RG.2.2.25876.30087.

[26] M. Dubois, H. Polinder, and J. A. Ferreira, "Comparison of generator topologies for direct-drive wind turbines," Nordic Countries Power and Industrial Electronics Conference (NORPIE), Jun. 2000.

\section{BIOGRAPHIES OF AUTHORS}

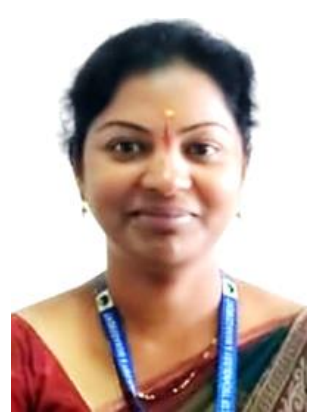

Kalpana Anumala (D) SC SC P is a Research Scholar in Electrical and Electronics Engineering Department at VNR Vignana Jyothi Institute of Engineering and Technology, JNTU, Hyderabad, India. She received B.Tech and M.Tech degrees in Electrical Engineering from JNTU, Hyderabad, India in 2005 and 2012, respectively. She currently pursuing her PhD at VNR Vignana Jyothi Institute of Engineering and Technology, JNTU, Hyderabad, India. She can be contacted at email: anumala.kalpana@gmail.com.

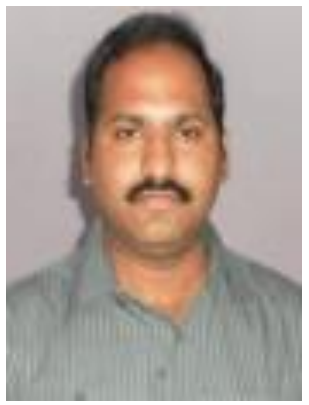

Ramesh Babu Veligatla (iD $\mathrm{SC}$ P is Associate Professor in Electrical and Electronics Engineering Department at VNR Vignana Jyothi Institute of Engineering and Technology, JNTU, Hyderabad, Hyderabad, India. He received B.Tech, M.Tech and $\mathrm{PhD}$ degrees in Electrical Engineering from JNTU, Hyderabad, India in 1998, 2004 and 2018 respectively. He has 20+ years of teaching experience in Electrical Engineering. His research interests include Electrical machines, drive control. He currently working inVNRVignana Jyothi Institute of Engineering and Technology, JNTU, Hyderabad, India. He can be contacted at email: rameshbabu_v@vnvjiet.in. 